\title{
A SOLUÇÃO DO PROBLEMA DA POBREZA ATRAVÉS DOS ÓRGÃOS DE VIGILÃNCIA NA FILOSOFIA DO DIREITO DE HEGEL ${ }^{1}$ \\ [The solution of poverty through the surveillance agencies in Hegel's Philosophy of \\ Right]
}

\author{
Pedro Geraldo Aparecido Novelli²
}

\begin{abstract}
Resumo: O presente texto tem por objetivo considerar uma possível solução da pobreza segundo o filósofo G.W.F. Hegel (1770-1831). Hegel se detém sobre o tema que, para ele, é muito mais um problema a ser seriamente considerado, em sua obra Linhas Fundamentais da Filosofia do Direito de 1821, na seção dedicada à eticidade e aí na subseção sobre a sociedade civil burguesa. Hegel elenca, ao longo da seção mencionada, inúmeros procedimentos adotados ao longo da história e em diferentes sociedades para se tentar resolver o problema da pobreza. Aqui se procura analisar uma delas que seria através dos órgãos de vigilância denominados por Hegel de "Polizei", ou seja, polícia. O termo guarda poucas relações com a compreensão atual de polícia sendo muito mais um órgão de fiscalização dos serviços públicos. Para Hegel a "Polizei" não se apresenta como uma solução definitiva, mas corretiva e momentânea, pois não atua sobre a causa da pobreza que é o modo de organização da sociedade civil burguesa.
\end{abstract}

Palavras-chaves: bem-estar, sucesso, paz

\begin{abstract}
The present text aims to consider a possible solution to poverty according to the philosopher G.W.F. Hegel (1770-1831). Hegel takes such theme in consideration that, for him, is much more a problem, which should be seriously treated, in his work Elements of the Philosophy of Right, published in 1821 , in the section dedicated to the ethical life and here in the subsection about the civil society. Hegel sets in the mentioned section different procedures adopted in history and in different societies to solve the problem of poverty. In this paper it will be analyzed one of the solutions named by Hegel as the "Polizei", i.e., the police. This term has not much to do with the modern term Police and it is much more an organization that supervises the public services. For Hegel the "Polizei" is not a definite solution but a corrective and momentary one because it does not act upon the cause of poverty that is the way the civil society is organized.
\end{abstract}

Keywords: well being, success, peace

\section{INTRODUÇÃO}

A pobreza é um problema? Por que, quando e para quem ela seria um problema? Como lidar com a pobreza? Poderia ela ser solucionada de algum modo? A pobreza não é um tema exclusivo da filosofia, aliás, a filosofia nem sempre se deteve sobre ela. O filósofo alemão

\footnotetext{
${ }^{1}$ Em honra do Dr. Holger Glinka pela atenção e ensinamentos.

${ }^{2}$ Professor Assistente-Doutor do Departamento de Filosofia da Faculdade de Filosofia e Ciências UNESP - Campus de Marília.
} 
G.W.F. Hegel (1770-1831) é um dos primeiros, senão o primeiro, a notar seu alcance sóciopolítico-econômico. A pobreza é considerada por Hegel, particularmente, em sua obra Linhas Fundamentais da Filosofia do Direito de 1821 na seção dedicada à eticidade e aí na subseção sobre a sociedade civil burguesa, que é caracterizada como o reino das carências recíprocas. É interessante observar que Hegel ao situar e tratar da pobreza no momento da sociedade civil burguesa deixa entender que se fala aí da origem e perpetuação da pobreza. Esta não seria, portanto, causada nem na família nem no Estado.

No entanto, tais instâncias não são independentes umas das outras, pois elas se encontram interrelacionadas de modo que, apesar de se possível distinguir umas das outras, ao mesmo tempo elas não podem ser vistas em completo isolamento.

Mas, por que a pobreza não é causada nem na família nem no Estado? Na família os membros são mantidos pelo sentimento que os envolve e que inibe a exclusão e ou desconsideração ou ainda a entrega à própria sorte. Paira sobre cada um dos membros da família a determinação da coletividade muito mais do que as determinações particulares.

No Estado os membros são mantidos também pela perspectiva coletiva diante da qual os indivíduos devem se submeter. Tanto na família quanto no Estado reina o comum como interesse ou o interesse do comum. Já na sociedade civil burguesa o que há de comum é o interesse ou o interesse é tomado como o comum. Na família cada um é acolhido independente de sua contribuição assim como no Estado mesmo o desocupado não é excluído nem execrado como indesejável. Na sociedade civil burguesa cada um deve buscar sua independência financeira contribuindo com a riqueza de todos. Na medida em que alguém não age segundo esta orientação e por qualquer motivo é excluído temporária ou permanentemente da atividade produtiva ele é automaticamente deixado de lado, pois ele não interessa de qualquer modo nem em qualquer situação.

Seria precipitado concluir que a sociedade civil burguesa não faz nada a respeito da pobreza, pois tanto na família quanto no Estado o cuidado com o pobre é movido respectivamente pelo afeto e sentimento que não deseja perder um de seus membros como família e, pela intervenção política por parte do Estado que se vê em todos os seus membros. A sociedade civil burguesa também se esforça para sanar ou diminuir a pobreza mesmo que seja pela busca da reintegração de seus "associados" à sua forma de existência. Uma das formas adotadas pela sociedade civil burguesa é através dos órgãos de vigilância ou a "Polizei", polícia, que tem na época de Hegel uma compreensão mais ampla do que se aplica na atualidade à instituição citada. Muito mais do que uma atividade de segurança exercida seja como ostensiva ou punitiva a "Polizei" incorpora na época de Hegel a fiscalização sobre os serviços prestados à sociedade como transporte, saúde, educação, etc. 
Em situações emergenciais como catástrofes naturais ou de convulsão social localizada "Polizei" interviria para reestabelecer a ordem vigente onde possa ter sido interrompida ou amenizando os efeitos danosos para certos seguimentos sociais.

A questão que interessa aqui é qual a efetividade de tal solução e em que medida se trata, de fato, de uma solução. Seria a "Polizei" capaz de solucionar a pobreza a partir da sociedade civil burguesa? Mas, que solução seria esta? Já não seria uma tentativa de solução que indicaria que sua efetivação se daria para além do momento da sociedade civil burguesa?

\section{I}

O texto original da Filosofia do Direito dedica alguns parágrafos à "Polizei" termo que poderia ser traduzido por polícia, porém Hegel diferencia entre "Polizisten" e "Polizei" sendo que o primeiro termo remete ao poder de polícia efetivado pela ação ostensiva e corretiva marcadamente militar. O termo "Polizei" também se refere às funções acima mencionadas, mas segundo o período histórico vivido por Hegel diz muito mais respeito à instituição que se dedicava ao controle das condições de vida em geral como, por exemplo, saúde pública, programas de vacinação e saneamento, controle de qualidade dos produtos alimentícios, limpeza das ruas, controle do trânsito de veículos, condições de transporte, etc. A "Polizei" é, para Hegel, o cuidado com a exterioridade contrastado pelo cuidado da interioridade da corporação. ${ }^{3}$ Tal instituição não é uma polícia, mas tem poder de polícia e sugere a idéia de polir, sanear, limpar. Como a liberdade se efetiva através da concretude da vida, a vigilância se coloca entre a possível realização da liberdade e a possibilidade das ameaças contra isso. Por um lado, ela garante a efetivação da liberdade como de fato possível e sua impossibilidade pela possível contraposição de intencionalidades, imprevistos e acidentes.

Se a vigilância atenta para as condições nas quais a liberdade se realiza as interferências naturais e espontaneamente danosas devem receber uma pronta manifestação no sentido de reestabelecer a ordem perturbada. No caso da pobreza acidental deveria haver, portanto, uma ação mais do que imediata de modo a recuperar as condições mínimas de sobrevivência. Em se tratando de atitudes e ou comportamentos nocivos à coletividade a reação deve ser ainda mais prontamente executada de modo a não instaurar forma alguma de tolerância ou de descrença por parte dos afetados direta e indiretamente. Obviamente há acontecimentos que são da ordem do natural e a aceitação dos mesmos se encontra entre a compreensão de que nem sempre se podem prever antecipadamente seus eventos, mas de igual modo não se trata de mera resignação ao acontecido e sim de uma ação que se antecipe enquanto prevenção. Para Hegel é sempre a partir do que se teve e do que se tem que se faz algo. O que pode vir a ser não se constitui em

\footnotetext{
${ }^{3}$ Hegel. 2005, S. 216.
} 
momento de atenção do conceito porque é uma possibilidade da possibilidade do possível. Sobre tal aspecto a própria filosofia não faz profecia alguma. ${ }^{4}$ Isso não significa que não se possa e nem se deva organizar perante o imprevisto, mas este somente é considerado de acordo com o que se tornou efetivo ou história.

A tarefa de fiscalização exercida pela "Polizei" não somente controla o que se passa, mas, concomitantemente, ao fazê-lo reforça o que existe como referência estabelecida. Qualquer pessoa que venha a ser jogada na faixa da pobreza seria então, imediatamente acolhida no reestabelecimento da existência tanto aceitável quanto desejável. ${ }^{5}$

Por mais que a "Polizei" procure restaurar o exercício da vida dos indivíduos empobrecidos ela precisa enfrentar um problema sério que é o abandono de si do indivíduo à pobreza, ou seja, o estado de pobreza intencional. A "Polizei" não parece possuir maior poder de ação do que com sua atenta fiscalização da educação infantil que atua sobre a formação do caráter e também prepara para a vida da virtude que é a retidão. $\mathrm{O}$ indivíduo precisa ser protegido de si mesmo, pois se, por exemplo, uma criança abandona seu processo de educação ou se permite que faça o que quiser, se com sua vontade e inteligência desenvolver somente interesses egoístas e exclusivos, o que se tem aí é a fonte de todos os males. ${ }^{6}$

Contudo, a "Polizei" precisa lidar com uma massa crescente de pobres e despossuídos que são todos os dias formalmente constituídos pelo movimento interno da sociedade civil burguesa. A "Polizei” não é uma exceção dentro da sociedade civil burguesa, mas é produto da mesma sociedade. Portanto, ela age sempre em consonância com a sociedade civil burguesa. Em relação à pobreza sua atividade preventiva, por mais eficaz que possa ser, não consegue ser mais do que um apagar de focos de incêndio que surgem aqui e acolá. Ainda conforme o próprio Hegel a floresta é vista, mas toda a atenção chega somente à árvore. ${ }^{7}$ A "Polizei” acaba por não

\footnotetext{
${ }^{4}$ G.W.F. Hegel. Vorlesungen über die Philosophie der Geschichte. Herausg. von Eva Moldenhauer und Karl Markus Michel. Frankfurt am Main: Suhrkamp, 1970, S. 114.

5 „Der Polzei weist Hegel ein weites und inhomogenes Aufgabenfeld zu. Zu ihren wichtigsten Aufgabe gehoren die Sicherung der öffentlichen Ordnung, die Gewerbeaufsicht, Industrieplannung, die Vorsorge für infrastrukturelle Maßnahmen - Hegel erwähnt Straßenbeleuchtung und Brückenbau -, die Gewähleistung der Zugänglichkeit von lebensnotwendigen Waren durch Verteilungs - und Steuervorschfriten sowie die Bereitstellung und Brückenbau -, die Gewähleistung der Zugänglichkeit von lebensnotwendigen Waren durch Verteilungs - und Steuervorschfriten sowie die Bereitstellung von Einrichtungen zur Einrichtungen zur Gesundheitspflege, zur Erziehung der Kinder und von Armenhäusern.“ Rolf-Peter Horstmann. Hegels Theorie der bürgerlichen Gesellschaft. In: Ludwieg Siep (Hrsg.) G.W.F. Hegel: Grundlinien der Philosophie des Rechts. Akademie Verlag: Berlin, 2014, S. 209.

${ }^{6}$ Hegel. E., $\$ 396$.

${ }^{7}$ Hegel. 2010, Prefácio, p. 34.
} 
conseguir mais do que remediar o estado da pobreza existente, porém será eficiente na garantia ao cuidado emergencial através da estrutura da sociedade civil burguesa. ${ }^{8}$

Apesar de tudo a atividade da "Polizei" não tem seu fundamento no sentimento de amor ao próximo que se institucionaliza pela Igreja Católica, pelo menos assim entende Hegel com respeito à sua época, pois os indivíduos são tomados como ocasião do direito. O sentimento religioso, por sua vez, valoriza a pobreza e dispensa cuidados de preservação, ou seja, recolhe a acolhe o pobre mantendo-o como pobre. O que se tem aqui é, segundo Hegel, o exercício da mera moralidade. ${ }^{9}$

Mas, como a "Polizei" fiscaliza a produção e o consumo, então ela poderia intervir de alguma forma sobre o comportamento da sociedade civil burguesa. A qualidade é extremamente importante, porém a quantidade também não pode ser deixada de lado visto que um consumo desigual resulta em bolsões de carência ou na disputa com conseqüências delicadas para o convívio social. A produção também não pode ser levada avante a qualquer preço porque os produtores também são consumidores. Quem produz pode ser capaz de produzir quase tudo, mas não terá a mesma satisfação com o consumo generalizado. A "Polizei” intervém numa tal situação para garantir o direito ao consumo que produz a existência. Os produtores sempre poderão se negar à produção que não pode ser partilhada por eles mesmo que minimamente ou de forma alternativa. Não poder consumir de forma alguma ou consumir insuficientemente se constitui numa situação a ser evitada. Aqueles que produzem podem e devem reivindicar seu direito ao consumo, todavia não podem generalizar sua carência como forma de resolvê-la, posto que os demais consumidores possuem os mesmos direitos. ${ }^{10}$

$\mathrm{Na}$ sociedade civil burguesa os indivíduos ficam divididos entre produtores e consumidores. Se, por um lado, os produtores não podem impor sobre os consumidores a cobrança de seus interesses particulares, por outro lado, os consumidores não podem igualmente esquecer que os produtores também são, por sua vez, consumidores. A ação da "Polizei" contra a greve dos produtores é uma ação a favor dos mesmos produtores. Não são os interesses da particularidade que deve reger os rumos da sociedade, mas a perspectiva do universal. Aí, tanto o interesse dos produtores quanto dos consumidores é contemplado, pois nem o privilégio de um nem o esquecimento do outro pode ser aceito sem que isso represente uma ameaça séria à sua integridade. $\mathrm{O}$ direito à greve não é uma exceção no direito, mas um alerta a respeito do

\footnotetext{
8 „Das Minimum der Subsistenz kann man in dem Armenanstalten, Hospitälern kennen lernen, da wird nur das Notwendigste gereicht, es zeigt sich da, was fúr das geringste Maß an Bedürfnissen inder bürgerlichen Gesellschaft angesehen wird." Hegel. 1974, S. 608.

${ }^{9}$ Hegel. 1974, S. 607.

${ }^{10}$ „Die Gesellen können sich verabreden, nicht um den bisherigen Lohn zu arbeiten, dies kann die Polizei nun nicht zugeben. [...] [d]er Zweig den sie übernommen haben muß befriedigt werden, es ist ihre Pflicht zu leisten, das Publikum hat einen Anspruch ihre Arbeit und kann dasselbe geltend machen." Hegel. 1974, S. 598.
} 
risco sob o qual o direito se encontra. Através da sua manifestação a "Polizei" recebe um claro indicativo da necessidade de sua intervenção para o reestabelecimento da universalidade. De certa forma a "Polizei" intervém no sentido de evitar e ou cercear o que já grassa na sociedade civil burguesa que é o estado de luta de todos contra todos. Muito embora este aí ainda perdure o que se obtém minimamente é sua observação sob o controle da totalidade. ${ }^{11}$

A intervenção sobre relação produção-consumo objetiva evitar o desequilíbrio entre essas duas interdependentes instâncias o que, no entanto, não significa que a instituição reguladora não se deixe influenciar pelas forcas de uma e de outra. Segundo Hegel não pode haver aí isenção alguma no sentido de não envolvimento e ou reconhecimento das necessidades e interesses tanto de produtores quanto de consumidores. Por isso, a "Polizei" deve e pode intervir no processo econômico de modo a garantir sua continuidade que não se traduz num equilíbrio constante, mas muito mais num estado de estabilidade marcado por uma tensão contínua entre o que se quer e o que pode vir a ocorrer a partir do que se quer. "É sempre possível dar-se a oposição entre os diversos interesses dos produtores e dos consumidores; e, embora, no conjunto, as corretas relações por eles mesmos sejam estabelecidas, ainda poderá ser conveniente uma regulamentação intencional superior às duas partes. A legitimidade de tal regulamentação (impostos sobre gêneros de primeira necessidade) para casos particulares justifica-se pelo fato de, na utilidade cotidiana e universal que possuem, as mercadorias serem oferecidas não ao indivíduo como tal, mas ao indivíduo como geral, ao público; o direito que este tem de não ser enganado, o exame das mercadorias, pode ser representado e assegurado pelos poderes públicos, como uma função coletiva. Mas o que, sobretudo, torna necessárias uma fiscalização e uma direção universais é a dependência em que vastos ramos industriais estão de circunstâncias exteriores e de combinações longínquas que não oferecem uma visão de conjunto aos homens que a elas se encontram ligados e sujeitos." 12

Apesar da intervenção na economia interna Hegel reconhece ainda os limites de seu alcance porque o processo de produção e consumo num Estado é afetado pelas relações que este estabelece com outros Estados. Com isso se explicita o que Hegel afirma sobre a sociedade civil burguesa, ou seja, que ela extrapola os limites de sua determinação somente numa cultura ou povo para se fazer expressão de uma generalidade histórica nos mais diferentes tempos. "Nesta dialética que lhe é própria, a sociedade civil é impelida para lá dela mesma; tal definida sociedade é obrigada a procurar fora de si os consumidores e, portanto, os meios de subsistir, recorrendo a outros povos que lhe são inferiores nos recursos que ela possui em excesso, em geral na indústria." ${ }^{13}$ A efetividade da intervenção da "Polizei" nesse contexto não se dá pela

\footnotetext{
${ }^{11}$ Hegel. 2010, § 289.

${ }^{12}$ Hegel. 2010, § 236.

${ }^{13}$ Hegel. 2010, § 246.
} 
sua completa determinação porque cada Estado considera também seus próprios interesses. Mesmo assim é possível uma ação formal que cerceie tanto a constituição quanto a propagação da pobreza. No embate entre os diferentes Estados haverá sempre o sacrifício imposto sobre uma parte ou outra e talvez sobre uma totalidade. Porém, o que é exigido daqueles que se encontram situados no processo de produção e de consumo e dele obtém satisfação regular não é comparável aos que estão à margem do mesmo processo. Os primeiros serão confirmados no estado em que se encontram enquanto que os últimos serão socorridos e, possivelmente, reintroduzidos no campo da satisfação. ${ }^{14}$

A "Polizei" combate os excessos da sociedade civil burguesa que resultam em exclusão na forma social da pobreza, mas na medida em que ela é também uma organização da própria sociedade civil burguesa ela se encontra condicionada por essa estrutura. Os pobres somente deixam de ser aí o que são sendo reintegrados à ordem que os desintegrou. Nessa má infinitude a solução esperada não se efetiva a não ser que se possa ir para além da mesma sociedade civil burguesa.

Para Hegel nenhuma das perspectivas até aqui elencadas possuem caráter de solução. Se, a pobreza é formada pelo estabelecimento premente da necessidade e da indeterminação do acaso, então seria necessária uma regulamentação que se impusesse sobre estas manifestações. Isto somente pode ser feito, segundo Hegel, pelo Estado e no Estado. O Estado é a explicitação histórica e universal de que o homem é sujeito de direito independentemente de toda e qualquer contingência que afete e determine como, por exemplo, ser ou não cristão, ser ou não alemão, ser ou não rico, etc. Nenhuma outra determinação se sobrepõe à determinação de ser pessoa no Estado. "Cumpre à cultura, ao pensamento como consciência do indivíduo na forma do universal, que eu seja concebido como uma pessoa universal, termo em que todos estão compreendidos como idênticos.

Deste modo, o homem vale porque é homem, não porque seja judeu, católico, protestante, alemão ou italiano. Tal conscientização do valor do pensamento universal tem uma importância infinita, e só se torna um erro quando cristaliza na forma do cosmopolitismo para se opor à vida concreta do Estado. " ${ }^{15}$ A garantia do direito se dá efetivamente na vida que se tem no Estado. Não basta aí um mero anúncio do direito que não seja afirmado e confirmado na vida de modo determinado, isto é, o direito precisa ser experimentado, vivenciado, "tocado" pelo sujeito. Nem a pobreza nem a riqueza é, no Estado, segundo Hegel, condição para o direito, mas

${ }^{14}$ Riedel. 1969, S. 161.

${ }^{15}$ Hegel. 2010, § 209. 
o direito, sim, é condição para uma e para outra. A imposição da pobreza sobre o direito se constitui numa ausência de direito quando o direito deveria ainda ser efetividade. Nesse sentido, se, a pobreza assim como a riqueza se apresenta como uma ameaça ao direito se faz necessária a pronta regulamentação por parte do Estado. Isso significa que o Estado não pode se deixar confundir em sua universalidade com a particularidade da sociedade civil burguesa. "Quando se confunde o Estado com a sociedade civil, destinando-o à segurança e proteção da propriedade e da liberdade pessoais, o interesse dos indivíduos enquanto tais é o fim supremo para que se reúnem, do que resulta ser facultativo ser membro de um Estado. Ora, é muito diferente a sua relação com o indivíduo. Se o Estado é o espírito objetivo, então só como membro é que o indivíduo tem objetividade, verdade e moralidade. A associação como tal é o verdadeiro conteúdo e o verdadeiro fim, e o destino dos indivíduos está em participarem numa vida coletiva; quaisquer outras satisfações, atividades e modalidades de comportamento têm o seu ponto de partida e o seu resultado neste ato substancial e universal." ${ }^{16}$ Muito embora o Estado contemple em si a diversidade ele não pode permitir que a diferença se estabeleça como uma determinação excludente. No Estado, tanto a riqueza quanto a pobreza se apresentam como resultantes da acumulação e da concentração de satisfação e da insatisfação. Por um lado, a riqueza concentra os bens da produção e do consumo, por outro lado, concentra a pobreza a exclusão de um e de outro. Desse modo, ambas se constituem em expressões do privado no qual não há inclusão voluntária, pois ricos não desejam, obviamente, a saída de sua situação e os pobres, por sua vez, não saem de seu estado simplesmente porque e quando querem. A oposição entre as vontades não se dá senão como embate de vontades que se querem diferentemente. Hegel toma a concentração de bens como fundada sobre o luxo que é a necessidade do desnecessário. Pobres também representam algo desnecessário e se fundam sobre a necessidade do necessário. Na sociedade civil burguesa o trabalho é visto como a fonte da satisfação o que significa que aqueles que se encontram satisfeitos são aqueles beneficiados pelo envolvimento direto com o trabalho. ${ }^{17} \mathrm{Em}$ contrapartida aqueles que não se envolvem com o trabalho acabam por desembocar no estado de insatisfação. Os que trabalham fazem por merecer o que recebem e os que não trabalham igualmente fazem por merecer a vida que tem. Essa é a lógica esperada a partir tanto pelo lado da concentração de renda, bens ou de satisfação quanto do lado da concentração da carência, da insatisfação. Contudo, a relação entre a concentração de satisfação e da insatisfação não é regulada pelas vontades particulares. ${ }^{18}$ Os que acumulam satisfação não reduzem voluntariamente a acumulação e não podem se orientar na direção da menor

\footnotetext{
${ }^{16}$ Hegel. 2010, § 258.

${ }^{17}$ Hegel emprega o termo ,jogador“ ao se referir aqueles que se beneficiam do acaso na sociedade civil burguesa. "Er befindet sich in dem Fall eines Spielers.” Hegel. 2005, S. 230.“ [...] als Erwerb [...] ohne Arbeit [...] durch die Zufälligkeiten bloß äußerlicher Verhältnisses.” Hegel. 2010, § 178.

1818 „Schlechtin Privatperson kann der Mensch nicht sein.“ Hegel. Philosophie des Rechts. Die Vorlesung von 1819/1820 in einer Nachschrift. Hrg. von Dieter Henrich. Frankfurt am Main: Suhrkamp, 1983.
} 
acumulação porque esta não se caracteriza pela diminuição. Os que acumulam a insatisfação desejam diminuir ou abandonar a situação em que se encontram, porém o que querem é o ingresso no estado de acumulação da satisfação. ${ }^{19}$

A construção estrutural da Filosofia do Direito de Hegel expõe o desenvolvimento dialético especulativo, triádico, da liberdade. A vontade, por exemplo, que se sabe livre percorre a senda do em si, para si e em si e para si. ${ }^{20}$ Essa senda é a mesma, certamente assim se pode dizer, que também pode ser vista nos diferentes momentos do direito abstrato, da moralidade e da eticidade. No momento da eticidade se dá também a divisão entre família, sociedade civil burguesa e Estado. A sociedade civil burguesa pode, sem se constituir num exagero, ser identificada com o segundo momento da vontade livre, isto é, "für sich" e com o momento da moralidade (Moralität). ${ }^{21}$ A sociedade civil burguesa se relaciona consigo mesma e se toma como resultado de si mesma e determinada pela subjetividade que arbitra sobre o que deve ser. Ela assume a independência da autodeterminação e aí não há espaço para a dependência que seja aquela da infância que é preparada para a liberdade para si.

“[...] a disposição moral objetiva consiste na probidade e na honra profissionais e, graças a elas, cada um faz de si membro de um elemento da sociedade civil, por sua determinação individual, pela sua atividade, sua aplicação e suas aptidões. É enquanto tal que cada um se mantém e só por intermédio do universal se subsiste na vida e se é reconhecido tanto na própria representação como na dos outros."22

O que Hegel mostra em sua Filosofia do Direito sobre a sociedade civil burguesa é que esta se move principalmente por uma compreensão econômica peculiar. Marcuse viu a Filosofia do Direito de Hegel como a expressão "[...] a filosofia da classe média que alcançou uma plena autoconsciência”. ${ }^{23}$ A sociedade civil burguesa resultante das revoluções industrial e francesa aparece como a realização da razão. Essa compreensão hegeliana não se dissocia da sua imediata diferenciação entre essa forma de organização social e o Estado. Filósofos como

\footnotetext{
${ }_{19}$ Joel Anderson. Hegel's Implicit View on How to Solve the Problem of Poverty: The Responsible Consumer and the Return of the Ethical to Civil Society. In: Robert R. Willians (Hg.). Beyond Liberalism and Communitarism. Studies in Hegel's Philosophy of Right. New York, 2001.

${ }^{20} \mathrm{An}$ sich, für sich und an sich für sich.

${ }^{21}$ „Im Recht sind die Menschen lediglich als formell freie Personen anerkannt in der Moralität aber kommen sie auch als Subjekte, d.h. als individuelle, wollende und handelnde Menschen zur Geltung." Josef Derbolav. Hegels Theorie der Handlung. In: Materialen izu Hegels Rechtsphilosophie. Bd. 2. Hg. von Manfred Riedel. Frankfurt am Main: Suhkamp, 1975, S. 204.

${ }^{22}$ Hegel. 2010, § 207.

${ }^{23}$ H. Marcuse. Razão e Revolução. Ou ainda com interpretações semelhantes Ritter. J. Metaphysik und Politik. Studien zu Aristoteles und Hegel. Frankfurt am Main: Suhrkamp, 1969; Riedel. M. Studien zu Hegels Rechtsphilosophie. Frankfurt am Main: Suhrkamp, 1969; Cesa. C. Hegel filosofo polüitico. Napoli: Guida Editore, 1976 e Ripalda. J.M. Fim del classicismo. A vueltas com Hegel. Madrid: Trotta, 1992.
} 
Hobbes (1642), Locke (1690 Of Political or Civil Society) e até Kant (1797 § 46, 432) empregam os termos indistintamente e Hegel se dissocia destes ao reconhecer aí atividades distintas do público. Para Hegel a sociedade civil burguesa se caracteriza pelo individualismo na busca pela satisfação das necessidades, pelo gozo da satisfação e as comodidades que daí advém. ${ }^{24}$ Na medida em que a sociedade civil burguesa é identificada com sua determinação econômica se evidencia sua despolitização. Ela não deixa de ser espaço e momento da política, mas pretere isso em favor da economia pela qual se rege através da insistente grita pela autossuficiência na forma da não intervenção por parte do Estado. ${ }^{25}$ Numa estrutura social marcada pela atomização na qual cada um é por si não se pode esperar que a resolução da pobreza possa se dar pela mesma atomização. Sendo o interesse pessoal o determinante não há como pretender aí um tratamento da insatisfação que não seja pela empreitada de reingresso no processo interminável da satisfação. A contradição na qual a sociedade civil burguesa se encontra é a de que cada um busca sua própria satisfação acabando por contribuir para a satisfação de todos e, ao mesmo tempo, também contribui para que a insatisfação se estabeleça, pois não há o suficiente para todos. O próprio conceito de justiça se modifica aqui e se liga ao merecimento que se obtém através da inserção no processo de autodeterminação pelo trabalho. Quem não trabalha não deve comer! Contudo, o status jurídico que os membros da sociedade civil burguesa superam, segundo Hegel, é a abstração kantiana. ${ }^{26}$ "Ser meramente egoísta (selbstsüchtig) já não é reprovável na sociedade humana. Quanto mais um homem gasta pata si mesmo, mais ele satisfaz as necessidades de uma multidão de outras pessoas. Neste gasto enorme (Verschlingung) tudo está relacionado; uma indústria altamente complicada. Numa sociedade educada de tal forma, ingressa no lugar da mera caridade outra maneira do cuidado mútuo, que em si parte mais da consideração do interesse pessoal posto que cada um deve seu pão à sua própria atividade." ${ }^{27} \mathrm{O}$ duplo aspecto da sociedade civil burguesa pelo qual cada um faz para si e igualmente para todos mesmo que não queira e que estabelece uma ação guiada conscientemente pela diferença produz a dialética da satisfação e da insatisfação. "O que os ingleses chamam confortável (comfortable) é algo inesgotável e que prossegue até o infinito já que toda comodidade mostra novamente sua incomodidade e estas invenções não tem nunca um fim (Ende). Não há, pois uma necessidade para quem as tem de uma maneira imediata, senão que muito mais é produzida por aqueles que buscam uma ganância com seu surgimento." ${ }^{28} \mathrm{Um}$ trabalho que se fragmenta em inúmeras manifestações que se direcionam para as mais diferentes

\footnotetext{
${ }^{24}$ Hegel. 2010, § 187.

25 Blank. Concepts of civil society in pre-modern Europe. In: Kaviras, S. e S. Khilvani (eds.) Civil Society. History and Possibilities. Cambridge: Cambridge University Press, 2001; Schröder. W. Zur Interpretation des Hegelschen Begriffs bürgerliche Gesellschaft. In: Hegels Jahrbuch (1971), pp. 133-147, Hamburg: Akademie Verlag; Horstmann. R. Über die Rolle der bürgerlichen Gesellschaft. In: Hegels politischer Philosophie. In: Hege Studien 9 (1974), pp. 209-240.

${ }^{26}$ Kant. Der Metaphysik der Sitten. Frankfurt am Main: Suhkamp, 1797, §§ 46, 47 e 49.

${ }^{27}$ Hegel. 1974, 4, § 199. (Tradução livre do autor)

${ }^{28}$ Hegel. 1970, § 191, Z.
} 
produções sem que se saiba a quem se destina se torna uma atividade abstrata que obtém a satisfação de quem produz através da insatisfação de quem poderá vir a consumir. A insatisfação é, portanto, esperada e até desejada. Ela é o sustentáculo da possibilidade de satisfação que, por sua vez, produz a insatisfação das mais variadas formas e maneiras. ${ }^{29}$ A insatisfação é produzida com a intenção de se obter a satisfação. Contudo, não há como garantir que toda insatisfação seja sanada, pois isso se dá através do consumo do que é produzido. O que se tem é um problema duplicado, pois, por um lado, nem tudo é consumido e, por outro, nem todos conseguem consumir. Além disso, o que é produzido não satisfaz do mesmo modo, mas diferentemente. Se, por exemplo, a necessidade de se alimentar precisa ser satisfeita, ela não é satisfeita com o mesmo produto para todos. Talvez todos possam vir a comer, porém não obrigatoriamente o mesmo. Algo ainda mais sério é o fato de que nem todos conseguirão de forma alguma acesso ao alimento. Mesmo que tais situações fossem tomadas como possibilidades, ainda que remotas, não se pode evitar que se constituam enquanto possibilidades e, portanto, como o que a realidade pode vir a ser. Precisamente esse controle a sociedade civil burguesa não tem sobre si mesma. ${ }^{30}$

Produção e consumo são as duas faces da sociedade civil burguesa e constituem também uma divisão no processo de produção da satisfação. Entre os produtores existe uma divisão de tarefas e de produtos e, de igual modo, entre os consumidores há a divisão de interesses em relação ao que é a satisfação. Diferentemente da família a sociedade civil burguesa individualiza os interesses e desperta a crença do único, do que é para o eu. O processo pulverizado de trabalho faz com o eu se veja em algo que somente ele produz separadamente dos demais. Seu trabalho, certamente, afeta os outros, mas sua particularidade é afirmada no seu isolamento na cadeia de produção. Inserido no processo de produção o indivíduo empreende a busca de sua satisfação singular, porém se vê submetido às condições desse processo sobre as quais ele não necessariamente pode claramente interferir. "A necessidade constitui um estranho poder sobre o qual ninguém pode fazer coisa alguma, um poder do qual depende se o excedente que cada um tem significa para ele uma satisfação total da necessidade." ${ }^{31}$ Hegel também reconhece que aquele que busca sua satisfação inserido no processo de produção e consumo da sociedade é vitimado pela mecanização o que exige do indivíduo ainda mais submissão ao processo do qual faz parte. "Quanto mais mecânico o trabalho se torna, menos valor possui e mais o trabalhador deve trabalhar desta maneira mecânica." 32 É oportuno mencionar que a sociedade civil burguesa aparece nas Linhas Fundamentais da Filosofia do Direito de Hegel com uma divisão triádica interna: o sistema das

29 „, O homem nao fabrica mais o que ele necessita.“ G.W.F. Hegel. Jenaer Systementwürfe I. Hrg. von K. Düssing und H. Kimmerle. Hamburg: Felix Meiner Verlag, 1975, S. 321.

${ }^{30}$ Hegel. Enciclopédia. $\S 84$, A. e $\S 95$.

${ }^{31}$ G.W.F. Hegel. System der Sittlichkeit. Hrg. von Horst Brandt. Hamburg: Felix Meiner, 2002, S. 74.

${ }^{32}$ Hegel. Jenaer I, S. 321. 
necessidades, a administração da justiça e a corporação e a justiça. Já se considerou aqui o papel da polícia e da corporação, mas cabe ressaltar a caracterização da necessidade que é considerada por Hegel com dois termos importantes: "Notwendigkeit" e "Bedürfnis" ambos podendo ser traduzidos por necessidade. Contudo, "Notwendigkeit" remete à ideia geral de necessidade e não se deixa exaurir em qualquer forma mais específica de necessidade enquanto que "Bedürfnis" indica muito mais a necessidade física mais imediata como comer, beber, abrigarse, etc. Tal diferenciação deve ser levada em conta para a compreensão da determinação da sociedade civil burguesa, ou seja, de que a satisfação de toda e qualquer necessidade enquanto "Bedürfnis" não implica na superação da necessidade enquanto "Notwendigkeit". Assim, por mais que sejam satisfeitas as "Bedürfnisse" sempre se permanece na "Notwendigkeit". No entanto, a permanência na "Notwendigkeit" pode resultar na satisfação em relação à "Bedürfnis" se se está integrado ao processo de obtenção da satisfação. Os que acumulam satisfação permanecem na "Notwendigkeit", mas se encontram, ainda que momentaneamente, devido à contingência do sistema econômico, libertos da "Bedürfnis". Aqueles que não tem seu lugar na "Notwendigkeit" padecem ainda mais com a "Bedürfnis", pois nem a satisfação imediata da insatisfação são capazes de experimentar. Fora do sistema das necessidades (System der Notwendigkeit) ${ }^{33}$ estes se encontram ainda mais necessitados. A satisfação das necessidades mais imediatas é, segundo Hegel, momento da liberdade e de sua constituição histórica, pois o homem deixa a submissão das condições dadas pela natureza para se autodeterminar. Ele não mais se satisfaz com o que está disponível, mas dispõe para si a satisfação através do trabalho. ${ }^{34}$ Os que são atirados para fora do sistema da "Notwendigkeit" e que, portanto, não obtém a subsistência diante do sistema da "Bedürfnis", são os que não somente experimentam a fome, mas, como diz Hegel, são atingidos eticamente e diminuídos em sua liberdade. ${ }^{35}$ Estes são os sem nome, sem direito, a multidão, os destituídos, os mais pobres, a plebe (Pöbel) os quais, como até se vê não ajudam em termos de solução. "A horripilante descrição da miséria, a qual impede a satisfação das necessidades, a encontramos especialmente em Rousseau e em alguns outros. Se trata de homens profundamente golpeados pela miséria de seu tempo, de seus povos, de homens que conhecem profundamente e expõem em modo comovedor a corrupção ética que brota, a raiva, a rebelião dos homens por sua miséria, pela contradição entre isso que eles estão em condições de pretender e as condições nas que se encontram, a exasperação por tal contradição, a vergonha por esta situação e com isso a amargura interna, a má vontade que

\footnotetext{
${ }^{33}$ Denis. H. Hegel, penseur politique. Láge d’Homme: Lauzane, 1989; Valcárcel. A. Hegel y la ética. Barcelona: Anthropos, 1988; Artola. J.M. Hegel, la filosofia como retorno. Madrid: Del Toro Editor, 1972; Winfield. R.D. Hegel's Challenge to the Modern Economy. In: Maker. W. Hegel on Economics and Freedom. Georgia: University Press, 1987; Rohbeck. J. Hegels System der Bedürfnisse und das Problem ihrer Entwicklung. In: Hegel Jahrbuch 1984, S. 155-164.

${ }^{34}$ Hegel. 2010, § 190.

${ }^{35}$ Hegel. 2010, § 240.
} 
nasce daí. Tudo isso é causado verdadeiramente pela sociedade civil." ${ }^{36}$ Hegel não restringe sua compreensão à situação francesa. ${ }^{37}$ Ao final de sua vida volta Hegel a essa questão em seu escrito "The Reformbill" indicando que "Na Inglaterra o contraste entre a monstruosa (ungeheuren) riqueza e a miséria é enorme." 38

A produção da e na sociedade civil burguesa tem também a pobreza como seu subproduto. Este produto não é objeto de desejo nem se constitui como desejo de consumo. Se não se quer o pobre também se quer o pobre porque ele não surge por si. Ele também pode ser fonte de satisfação se tomado como situação sobre a qual se investe. Mas, como sua produção é sistemática e constante ele também aprende a pobreza e ao ser permanentemente caracterizado enquanto tal se vê num processo de educação e ou formação para a pobreza. $\mathrm{O}$ empobrecimento se dá, então, em todos os sentidos, isto é, o pobre também se acostuma com a pobreza, com a indignidade, com a ausência do trabalho. $\mathrm{O}$ que se é resulta do que é feito para tanto. $\mathrm{O}$ abandono do que se é representa também um novo ser de si ou como diria Hegel um novo hábito (Gewohnheit) de si e de ser. ${ }^{39}$ Em sua Filosofia do Direito enfatiza Hegel que o processo de formação e ou educação se dá “[...] através da disciplina, aprender a se habituar”. ${ }^{40}$ Trata-se de uma aquisição histórica, portanto, não individual. É uma disposição que os homens desenvolvem entre si e de forma institucional o que é exemplificado por Hegel na corporação. ${ }^{41}$ A educação formalmente instituída é também uma clara demonstração de como o homem se quer. ${ }^{42}$

Habituar-se significa, para Hegel, passar da primeira natureza à segunda natureza, isto é, espiritual. A primeira natureza não deixará de existir e até se faz necessária, mas a existência em comum não será mais conduzida pela imediatidade dos instintos, e sim pelas escolhas da razão. As determinações instintivas se põem pela natureza ou o que seria o mesmo elas se dão de forma inerente aos sujeitos que se encontram mergulhados nessa realidade. A determinação do espírito é a autodeterminação de como se quer sempre em relação às determinações instintivas que cobram sua satisfação. A autodeterminação do espírito se confirma enquanto tal

\footnotetext{
${ }^{36}$ Hegel. 1974, 4, Ilting, S. 477.

37 „Em Londres [...], nesta cidade infinitamente rica, é a necessidade, a miséria, a pobreza tão espantosamente grande que não conseguimos imaginá-la.” Hegel. 1974, 4, Ilting, S. 494.

${ }^{38}$ Hegel. 1970, W.11, S. 93.

${ }^{39}$ C Malabou.. L’Avenir de Hegel. Plasticité. Temporalité. Dialectique. Paris, 1996.

40, ,...] durch Zucht, lernen und gewohnt zu werden.“"Hegel. 1970, § 132 N.

41 Bloch. E. Subjekt - Objekt. Erläuterungen zu Hegel. Erweiterte Ausgabe. Frankfurt am Main: Suhrkamp, 1962, S. 32 ff.

${ }^{42}$ Nicoli. F. Hegels Bildungstheorie. Grundlinien einer geisteswissenschfatlichen Pädagogik. Diss. Bonn, 1955.
} 
constantemente, como processo, segundo o que quer diante das possibilidades que se apresentam. ${ }^{43}$

Segundo Hegel o hábito se apresenta na medida em que a atividade tem sua intensidade diminuída, ou seja, enquanto o sujeito investe sobre sua existência para a obtenção da satisfação ele determina para si o que quer, mas uma vez isso tenha se estabelecido passa a dominar uma certa rotina na qual o sujeito se encontra em si. O hábito parece ser assim uma limitação da liberdade, pois o sujeito se entrega ao que estabeleceu e se deixa aí ser estabelecido. No entanto, o hábito também se constitui numa possibilidade para a liberdade porque é o sujeito que o cria e a liberdade também se apresenta através de uma certa constância. ${ }^{44}$

O hábito tem suas próprias referências e sustenta não somente a existência do indivíduo como também da sua coletividade. As referências se constituem em regras que disciplinam o desenvolvimento e podem ser deixadas de lado posteriormente porque foram incorporadas no que se faz. Por isso, escreve Hegel que o homem ético é inconsciente de si enquanto tal. ${ }^{45}$ Ao se falar de hábito fala-se não somente de uma disposição da alma, mas também do corpo, isto é, fala-se de uma disposição do sujeito em sua completude. Ele se sente posto para agir e desejoso de sua rotina. ${ }^{46}$ Não se trata de nenhuma ação mecânica, mas do que se sabe como o que se quer porque não se tem aqui a realização de algo desnecessário nem sem obstáculos, mas do exigente e por vezes de difícil efetivação.

A objetivação do direito abstrato com sua dependência da exterioridade e a subjetivação do mesmo direito na interioridade da moralidade são resultantes do hábito que na eticidade avança para a relação de completude entre o exterior e o interior enquanto um é negado e afirmado pelo outro ao mesmo tempo. Habituar-se à necessidade de que o direito não pode limitar-se à sua positividade e nem à intimidade do sujeito moral. O direito tem não somente seu conteúdo na moralidade, ou seja, no sujeito que livremente se determina, mas também na determinação exterior do que fazer. ${ }^{47}$

Aquele que se habituou por um processo repetidamente realizado, e que, com isso, chegou à sua segunda natureza, não se encontra isento da possibilidade de se habituar com o desinteresse. O hábito não pode, portanto, ser reduzido e ou identificado com o que seria visto como desejável e abonável. Aquele que está habituado a fazer, a agir, a trabalhar também está

43 „Die unmittelbare Empfindung als negiert gleichgültig“. ,[...] Abhärtung gegen äußerliche Empfindungen“ „,...] gegen Unglück“. „Gleichgültigkeit gegen die Befriedigung; die Begierden, Triebe werden durch die Gewohnheit abgestumpft“. ,[...] Form der Gewohnheit alle Arten und Stufen der Tätigkeit des Geistes umfasst.“ Hegel. 2005, E 3, §

${ }^{44}$ Hegel. 2005, § 395.

${ }^{45}$ Hegel. 2010, § 144.

${ }^{46}$ Hegel. 2010, § 158.

47 Won. Jue-Ho. Hegels Begriff der politischen Gesinnung, Zutrauen, Patriotismus und Vertrauen. Würzburg, 2002, S. 99. 
sujeito a habituar-se a não fazer, não agir e não trabalhar. Já que o hábito é uma aquisição que se dá pelo exercício, pela repetição, pela intenção, então a causa do mesmo não se encontra no sujeito habituado, mas no contexto que o habitua. Nesse sentido ao se considerar a questão da pobreza deve-se levar em conta que o pobre é levado a se habituar com a pobreza. Sendo a sociedade civil um organismo vivo qualquer órgão que dela for apartado poderá continuar a existir, porém não terá mais efetividade. É não sendo o que é, pois o que é remete ao seu parecer ser no qual já não mais é. ${ }^{48}$

\section{III}

O pobre por existir, porém sem ser, ou padecer um ser aí inorgânico experimenta a morte política do direito sem direito ou da mera afirmação do direito sem a sua subsequente confirmação no ser aí. A morte política é seguida pela morte social na sua transformação de necessidade (notwendig) para carência (bedürftigt). A massa de despossuídos permanece ao nível da possibilidade que se impossibilita marcada pela atividade da inatividade ou do conceito cuja realidade não coincide. $\mathrm{O}$ despossuído se encontra ou no conceito enquanto mera abstração ou na realidade indeterminada. Porque está apartado do organismo da sociedade civil burguesa o despossuído ou o pobre mais pobre (Pöbel) não se vê na posição de realização de si, pois sua vontade não possui nenhuma efetividade. Aqui se tem uma vontade que quer porque necessita e não necessita porque quer. ${ }^{49}$

A necessidade é, conforme já mencionado, intrínseca ao organismo, porém este continua sendo organismo segundo sua essência de organização e não se deixa diminuir pela necessidade. Pelo contrário, é aí que o organismo tem sua sustentação mesmo que seja obrigado a pagar o preço do desligamento por vezes de seus órgãos. O desligamento de um órgão não é o desligamento do organismo, mas a confirmação de que apartado dele não é possível uma existência que seja efetiva e não contingente e ou efêmera. Tal é a relação dos indivíduos ou dos grupos na sociedade civil burguesa que não pode absolutamente abrir mão de forma crescente e constante de seus membros, mas que também não pode se desdobrar na recuperação dos mesmos porque ela se confirma nos que estão integrados nela. $\mathrm{O}$ mesmo poderia ser dito em relação ao Estado com a diferença de que o Estado não pode expurgar nenhum de seus membros, nem mesmo os que por um momento tenham sido separados pela contingência e ou arbitrariedade das relações sociais sob o preço de deixar de ser a universalidade que a todos e

\footnotetext{
${ }^{48}$ Hegel. 2010, § 270, Z.

49 „Aber der häßlichste Mensch, der Verbrecher, ein Kranker und Kruppel ist immer noch ein lebender Mensch; das Affirmative, das Leben, besteht trotz des Mangels, und um dieses Affirmative ist es hier zu tun." Hegel. 1970, § 258.
} 
tudo contempla. "Ora, o Estado é essencialmente uma organização de membros que são, por si mesmos, círculos e nunca, nele, qualquer momento pode se mostrar como uma massa inorgânica." ${ }^{50}$ Com isso os despossuídos se constituem um perigo para o Estado não em si mesmos, mas para si mesmos e, nesse sentido, o Estado não pode permanecer indiferente a estes porque seria indiferente a si mesmo. "Se o corpo não confirma a alma, assim se tem aí algo faltando e carente." ${ }^{51}$ Em relação à palavra "faltando" e "carente" Hegel emprega o termo "Elend" que representa muito mais a necessidade física que obviamente não se dissocia do que se poderia denominar "não físico", mas o sofrimento pela privação é tão intensamente experimentada tanto quanto fosse possível tê-la somente no corpo. A pobreza extremada carrega a dupla privação das necessidades mais imediatas não satisfeitas e a privação do sujeito de si mesmo porque não se tem sob sua vontade e sua determinação. Atua sobre ele a primeira natureza reduzindo-o ao nível da animalidade porque premido pela satisfação das necessidades mais primárias. Ressaltando-se aí sua animalidade este também se vê privado de sua capacidade de transformar com suas mãos sua realidade e se torna presa do imediato. "Ein Wille, der nichts beschließt, ist kein wirklicher Wille; der Charakterlose kommt nie zum Beschließen. Der Grund des Zauderns kann auch in einer Zärtlichkeit des Gemüts liegen, welches weiß, daß im Bestimmen es sich mit der Endlichkeit einläßt, sich eine Schranke setzt und die Unendlichkeit aufgibt: es will aber nicht der Totalität entsagen, die es beabsichtigt. Ein solches Gemüt ist ein totes, wenn es auch ein schönes sein will. Wer Großes will, sagt Goethe, muß sich beschränken können. Durch das Beschließen allein tritt der Mensch in die Wirklichkeit [...].“ 52 A incapacidade do despossuído de se conduzir não é uma predeterminação do sujeito, mas uma apreensão a partir do que lhe é determinado de fora.

O movimento da economia da sociedade civil burguesa não é o movimento de inclusão, mas de exaustão de seus membros sendo que não poucos serão excluídos por terem sido exauridos. Não se entra por qualquer porta na sociedade civil burguesa. Nem todos os acessos são de livre ingresso. A porta da procura em relação à oferta é a entrada das massas assim como sua concomitante saída. Seu entrar é o seu sair. ${ }^{53}$

Mas, que vontade é a vontade do despossuído? Se, para Hegel a vontade é a efetivação do ser livre que se sabe e se quer, então se tem aí também um poder pelo querer. Contudo, a vontade na sociedade civil burguesa é a vontade do sujeito, dos sujeitos que se encontram no querer comum do interesse. O interesse do outro interessa se me interessa. Nem tudo que interessa a um é do interesse do outro. Importa que os interesses coincidam. Os despossuídos não parecem ser do interesse da sociedade civil burguesa, pois o que podem possuir nada

\footnotetext{
${ }^{50}$ Hegel. 2010, § 303.

${ }^{51}$ Hegel. 1970, § 1 Z.

${ }^{52}$ Hegel. 1970, § 13, Z.

${ }^{53}$ Eric Weil. Hegel et Létat. Cinq conférences suivies de Marx et la philosophie du droit. Paris, 1994.
} 
possuindo que desperte qualquer interesse. Eles, por sua vez, interessam-se muito pelo que a sociedade civil burguesa possui, porém sua vontade não é sua vontade e sim a vontade do possuidor. ${ }^{54}$ Que materialidade teria o despossuido que o fizesse ser visto? Seria a determinação de seu não possuir? Sem dúvida o despossuído aparece enquanto massa ou quantidade desprovida de qualidade. Sua presença é a de uma ausência que insiste em se fazer presente. Então, novamente, o despossuído está sem ser! Sua presença é a de um órgão sem corpo que se encontra muito mais submetido à morte eminente do que à qualquer possibilidade de vida. Seu espaço não é o do convívio na sociedade civil burguesa, pois não ocupa aí campo algum porque não tem nada a ver com o que interessa à sociedade civil burguesa. O despossuído caracteriza a vida depois da morte porque não participa da vida a não ser em suas sobras e restos e, por conseguinte, nem a morte é para ele uma efetividade. Sua vida após a morte é a da indeterminação, da descaracterização, da arbitrariedade da contingência. Ele não vive nem morre. Um movimento sem movimento, uma identidade sem identidade, um ser sem ser, uma negatividade sem negatividade, enfim, uma não suprassunção.

\section{Conclusão}

A afirmação evangélica de que sempre se terá pobres não explicita sob quais circunstâncias, isto é, sob qual sistema econômico, político e social isso se dará, porém não parece ser muito temerário ver aí a compreensão hegeliana de que a suprassunção da pobreza não tem seu lugar senão no âmbito do Estado, ou da universalidade realizada e realização do universal. Mas, qual Estado? Certamente o mais racional possível, segundo Hegel, que contemple em si todas as particularidades e que, precisamente por isso, se veja nessa em cada uma destas. Desse modo não se pode esperar, muito embora se deseje, que a pobreza possa ter sua suprassunção no momento da sociedade civil burguesa. O que se pode encontrar na sociedade civil burguesa enquanto solução para a pobreza é o seu desaparecimento, seja porque o pobre desaparece por sua eliminação, seja porque o pobre deixa de ser pobre para se tornar um não pobre. A suprassunção da

\footnotetext{
$54,[\ldots]$ die Materie [...] auf diese Weise [...] an und für sich nicht [existiert], sondern um zu dieser Gleichgültigkeit zu kommen, muss sie selbst zum Prädikate, zum aufgehobenen Moment herabgesunken sein. [...] An sich also ist die Materie heißt: sie ist nurihrer Abstraktion nach genommen." G.W.F. Hegel. Jenaer Realphilosophie Vorlesungsmanuskripte zur Philosophie der Natur und des Geistes von 18051806, hg. Johannes Hoffmeister. Berlin, 1969, S. 22.
} 
pobreza não implica nem na eliminação nem na transformação da pobreza, mas no reconhecimento da dignidade que não se ausenta daí e, por conseguinte, exige que se atente para a pobreza eliminando, isto sim, a carência e a necessidade determinantes. $\mathrm{O}$ estabelecimento da igualdade se for tomada em termos de possibilidade financeira não impede que alguém se coloque em estado de penúria. Por isso, o Estado, conforme Hegel o compreende, deve proteger o indivíduo de si mesmo. Mesmo assim não se tem a plena garantia de que deturpações não venham a ocorrer. Um processo de formação que eduque para a coletividade não pode massacrar as individualidades e suas peculiaridades, mas certamente pode e deve combater a imposição do particular sobre o universal ou do individual sobre o coletivo se o indivíduo não for senão a promoção do coletivo.

A solução para a pobreza por parte da sociedade civil burguesa, segundo Hegel, pelo menos uma delas, ou seja, como no presente caso, a solução por via dos órgãos de vigilância não possui efetividade senão momentânea porque não reforma situação alguma, mas tão somente busca restaurar a ordem social civil burguesa que o pobre com sua existência perturba ou subverte. Aqui o pobre precisa deixar de ser pobre e passar a ser um não pobre ou plenamente integrado à ordem social civil burguesa. Esta não deveria precisar socorrer os seus membros, pois estes não precisariam de socorro algum porque estariam se beneficiando da satisfação que se encontraria na sociedade civil burguesa. Se os órgãos de vigilância promovessem uma reforma para solucionar a pobreza isso afetaria a própria sociedade civil burguesa e sua organização, pois somente uma nova forma de relação precisaria ser implantada. Tal relação não se contentaria com a liberdade de mercado, mas com um mercado livre de determinações exclusivistas e de poderios que subjugam aos interesses particulares.

Os órgãos de vigilância não somente atentam para a manutenção da ordem da e na sociedade civil burguesa como também realizam o controle dos exageros da e na mesma ordem. Na mesma seção dedicada à sociedade civil burguesa Hegel faz notar a presença da constituição da exterioridade do Estado ou do Estado que é posto como adjacente à mesma sociedade para que seus excessos sejam evitados ou punidos. A necessidade de um controle sobre si ou sobre as relações travadas pelos interesses particulares faz com que a sociedade civil burguesa assuma um expediente de policiamento que não descuide dos desmandos e abusos. Nesse sentido os órgãos de vigilância tem seu reconhecimento na efetivação dessa atividade o que começa por colocar a solução da pobreza no momento da sociedade civil burguesa fora dela ou no 
momento do Estado mesmo que aí é a ainda seja o Estado subserviente à manutenção e preservação da dita sociedade.

O limite dos órgãos de vigilância aparece na sua incapacidade de lidar com a causa da pobreza que é a própria constituição da sociedade civil burguesa. A atuação se dá pontualmente sobre os efeitos ou focos de incêndio que precisam ser apagados sem que se possa preveni-los, pois é sabido que continuarão a aparecer mais cedo ou mais tarde.

Para Hegel os órgãos de vigilância representam o cuidado que a sociedade civil burguesa tem com os seus membros ou consigo mesma fazendo com que ela reapareça nos membros desgarrados. Ela não os recupera para além de si mesma, pois isso significaria assumir que há um além de si no qual a existência seria mais desejável e melhor o que conduziria a sociedade civil burguesa à sua extinção ou no mínimo ao reconhecimento de seu caráter de passagem para uma realidade mais promissora. Desde a perspectiva da sociedade civil burguesa o mundo é o que é e como foi feito pelos homens e não pode ser diverso do que é. Mas, se são os homens que fazem o mundo, então este pode sempre ser diverso do que tem sido. E, por que os homens não o fariam mais livre, igual e fraterno? A resposta não é muito difícil de ser obtida e se resume no convencimento de que é muito melhor se encontrar nos limites da sociedade civil burguesa do que para além dos mesmos.

Para tal convencimento os órgãos de vigilância desempenham um papel muito importante porque reconduzem os desgarrados ao reduto social civil burguês insistentemente, por exemplo, acompanhando o abandono da educação formal que mesmo crítica é motivada seja pelo diletantismo daqueles que não precisam trabalhar para garantir o estudo seja pela dificuldade de estudar por ter que trabalhar durante ou logo após o processo. A autonomia do indivíduo é sua característica na sociedade civil burguesa. Sua liberdade se dá pela sua capacidade de se manter com suas próprias forças e fazer o menor uso possível de recursos que não sejam os de sua autoria e responsabilidade. O problema é que isso pressupõe que haja espaço para todos e que, com afinco e empenho, mais cedo ou mais tarde todos conseguirão o que precisam e querem, mas para muitos pode ser mais tarde do que se imaginaria e até se esperaria.

\section{BIBLIOGRAFIA}


ANDERSON. J. Hegel's Implicit View on How to Solve the Problem of Poverty: The Responsible Consumer and the Return of the Ethical to Civil Society. In: Robert R. Willians (Hg.). Beyond Liberalism and Communitarism. Studies in Hegel's Philosophy of Right. New York, 2001.

ARTOLA. J.M. Hegel, la filosofia como retorno. Madrid: Del Toro Editor, 1972.

BLANK. Concepts of civil society in pre-modern Europe. In: Kaviras, S. e S. Khilvani (eds.) Civil Society. History and Possibilities. Cambridge: Cambridge University Press, 2001.

BLOCH. E. Subjekt - Objekt. Erläuterungen zu Hegel. Erweiterte Ausgabe. Frankfurt am Main: Suhrkamp, 1962.

CESA. C. Hegel filosofo polüitico. Napoli: Guida Editore, 1976.

DENIS. H. Hegel, penseur politique. Láge d’Homme: Lauzane, 1989.

DERBOLAV. J. Hegels Theorie der Handlung. In: Materialen izu Hegels Rechtsphilosophie. Bd. 2. Hg. von Manfred Riedel. Frankfurt am Main: Suhrkamp, 1975.

HEGEL. G.W.F. Philosophie des Rechts. Die Vorlesung von 1819/1820 in einer Nachschrift. Hrg. von Dieter Henrich. Frankfurt am Main: Suhrkamp, 1983.

HEGEL. G.W.F. Die Philosophie des Rechts. Vorlesung von 1821/22. Herausg. von Hansgeorg Hoppe. Frankfurt am Main: Suhrkamp, 2005.

HEGEL. G.W.F. Enciclopédia das Ciências Filosóficas em Compêndio. Trad. de Paulo Meneses. São Paulo: Loyola, 1995.

HEGEL. G.W.F. Frühe Schriften. Herausg. von Eva Moldenhauer und krl Markus Michel. Frankfurt am Main: Suhrkamp, 1999.

HEGEL. G.W.F. Jenaer Schriften 1801-1807. Herausg. von Eva Moldenhauer und Karl markus Michel. Frankfurt am Main: Suhrkamp, 1986.

HEGEL. G.W.F. Jenaer Realphilosophie Vorlesungsmanuskripte zur Philosophie der Natur und des Geistes von 1805-1806, hg. Johannes Hoffmeister. Berlin, 1969.

HEGEL. G.W.F. Jenaer Systementwürfe I. Hrg. von K. Düssing und H. Kimmerle. Hamburg: Felix Meiner Verlag, 1975.

HEGEL. G.W.F. Linhas Fundamentais da Filosofia do Direito. Trad. de Paulo Meneses et al. São Leopoldo: Loyola, 2010. 
HEGEL. G.W.F. System der Sittlichkeit. Hrg. von Horst Brandt. Hamburg: Felix Meiner, 2002.

HEGEL. G.W.F. Vorlesungen über die Philosophie der Geschichte. Herausg. von Eva Moldenhauer und Karl Markus Michel. Frankfurt am Main: Suhrkamp, 1970.

HEGEL. G.W.F. Vorlesungen über Rechtsphilosophie. 1818 - 1831. Edition und Kommentar in sechs Bänden von Karl-Heinz Ilting. Vierter Band: Philosophie des Rechts, nach der Vorlesungsnachschrift von K.G. Griesheims 1824/25. Der objektive Geist. Aus der Berliner Enzyklopädie zweite und dritte Auflage (1827 und 1830), Philosophie des Rechts Nach der Vorlesungsnachschrift von D.F. Staruß 1831 mit Hegels Vorlesungsnotizen. Stuttgart-Bad Cannstatt, 1974.

HORSTMANN. R. Über die Rolle der bürgerlichen Gesellschaft. In: Hegels politischer Philosophie. In: Hege Studien 9 (1974), Hamburg: Akademie Verlag.

HORSTMANN. R. Hegels Theorie der bürgerlichen Gesellschaft. In: Ludwieg Siep (Hrsg.) G.W.F. Hegel: Grundlinien der Philosophie des Rechts. Akademie Verlag: Berlin, 2014,

KANT. E. Der Metaphysik der Sitten. Frankfurt am Main: Suhkamp, 1797.

MALABOU. C. L'Avenir de Hegel. Plasticité. Temporalité. Dialectique. Paris, 1996.

Nicoli. F. Hegels Bildungstheorie. Grundlinien einer geisteswissenschfatlichen Pädagogik. Diss. Bonn, 1955.

MARCUSE. H. Razão e Revolução. Trad. de Marília Barroso. São Paulo: Paz e Terra, 2014.

NICOLI. F. Hegels Bildungstheorie. Grundlinien einer geisteswissenschfatlichen Pädagogik. Diss. Bonn, 1955.

RIEDEL. M. Der Begriff der Bürgerlichen Gesellschaft und das Problem seines geschichtlichen Ursprungs. In: Studien zu Hegels Rechtsphilosophie. Frankfurt am Main, 1969.

RIEDEL. M. Studien zu Hegels Rechtsphilosophie. Frankfurt am Main: Suhrkamp, 1969 ;

RIPALDA. J.M. Fim del classicismo. A vueltas com Hegel. Madrid: Trotta, 1992.

RITTER. J. Metaphysik und Politik. Studien zu Aristoteles und Hegel. Frankfurt am Main: Suhrkamp, 1969.

ROHBECK. J. Hegels System der Bedürfnisse und das Problem ihrer Entwicklung. In: Hegel Jahrbuch 1984, 
SCHÖDER. W. Zur Interpretation des Hegelschen Begriffs bürgerliche Gesellschaft. In: Hegels Jahrbuch (1971), Hamburg: Akademie Verlag.

VALCÁRCEL. A. Hegel y la ética. Barcelona: Anthropos, 1988.

WEIL. E. Hegel et Létat. Cinq conférences suivies de Marx et la philosophie du droit. Paris, 1994.

WINFIELD. R.D. Hegel's Challenge to the Modern Economy. In: Maker. W. Hegel on Economics and Freedom. Georgia: University Press, 1987.

WON. Jue-Ho. Hegels Begriff der politischen Gesinnung, Zutrauen, Patriotismus und Vertrauen. Würzburg, 2002.

Recebido em janeiro de 2016

Aceito em fevereiro de 2016. 